\section{$\underset{\substack{\text { hommes } \\ \text { \& migrations }}}{ }$}

\section{Hommes \& migrations}

Revue française de référence sur les dynamiques

migratoires

$1328 \mid 2020$

Les réfugiés dans l'impasse

\title{
Des Territoires (... et tout sera pardonné ?),
}

Texte et mise en scène de Baptiste Amann

\section{Mustapha Harzoune}

\section{Q OpenEdition}

\section{Journals}

\section{Édition électronique}

URL : https://journals.openedition.org/hommesmigrations/10977

DOI : 10.4000/hommesmigrations. 10977

ISSN : 2262-3353

\section{Éditeur}

Musée national de l'histoire de l'immigration

\section{Édition imprimée}

Date de publication : 1 janvier 2020

Pagination : $211-212$

ISBN : 978-2-919040-49-0

ISSN : 1142-852X

\section{Référence électronique}

Mustapha Harzoune, « Des Territoires (... et tout sera pardonné ?), », Hommes \& migrations [En ligne] 1328 | 2020, mis en ligne le 01 janvier 2020, consulté le 04 janvier 2023. URL : http:// journals.openedition.org/hommesmigrations/10977 ; DOI : https://doi.org/10.4000/ hommesmigrations.10977 


\section{Théâtre}

\section{Des Territoires (... et tout sera pardonné ?),}

texte et mise en scène de Baptiste Amann.

Revisiter la guerre d'Algérie sur fond d'émeutes urbaines dans un hôpital transformé en un plateau de tournage d'un film consacré à Djamila Bouhired, se jouer des temporalités, dire le multiple et le mutuel par une construction chorale, réintroduire ce drame dans l'histoire nationale, comme une blessure, un corps en état de mort cérébrale mais dont le cœur ne demande qu'à battre, et se retrouver, tous - Lyn et ses deux frères, Samuel et Hafiz, les amis Moussa et Naïlia -, non pas autour d'un mort mais pour célébrer la vie.

Des Territoires est une trilogie qui interroge depuis sa première livraison notre capacité à lutter et à aimer: "Tout faire pour éviter que / De toutes vies ne restent au bout du compte / Que des femmes et des hommes / Écrasés par la fatigue / Serrant contre le coeur une photo de famille, / Pour implorer le pardon de l'enfant qu'ils étaient. » Où est-il ce vaste et nécessaire amour, de soi et des autres, pour refuser les injustices de classes, de genres («l'inégalité la plus grande, la plus vieille, celle qui tient entre elles toutes les autres»), les relents d'une pensée coloniale. "La fatigue»! Lutter? Se révolter? Comment et pour quoi faire? Cette question est au cœur de cette œuvre protéiforme et fascinante, portée par la figure libertaire de Djamila Bouhired à qui Baptiste Amann prête ces mots blasphématoires: "Ordre m'est donné de déposer des bombes, je déposerai ces bombes. Mais que construiront comme pays les gens comme toi? De quel orgueil faudra-t-il vous extraire pour repartir à zéro?»

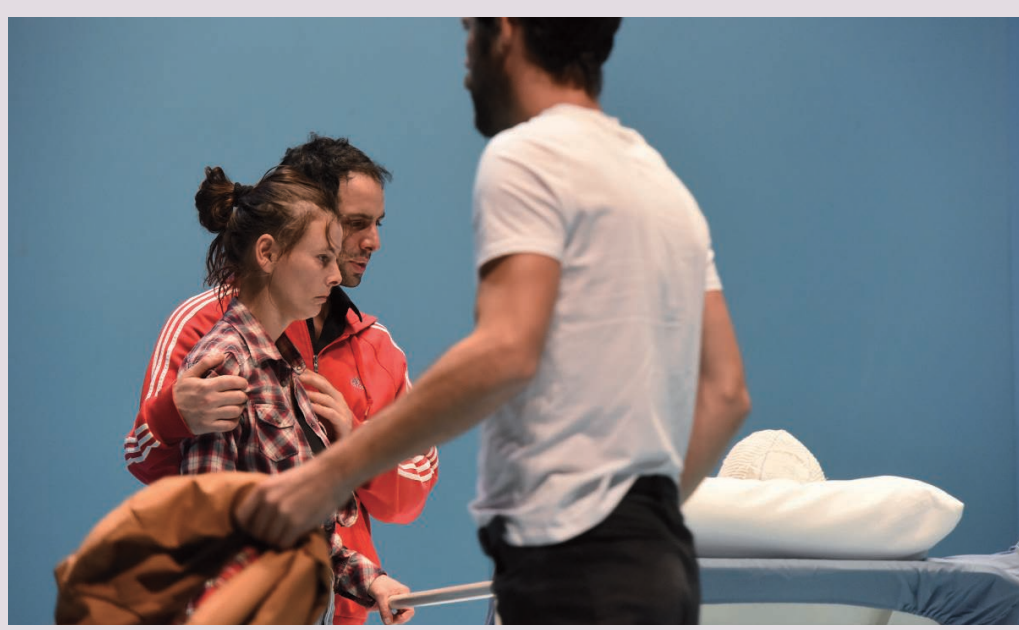

- Des territoires (... et tout sera pardonné ?). (C) D. R.

Sur le plateau, le spectateur découvre un studio de radio, une salle de réanimation, la salle d'attente d'un hôpital, un couloir, un décor et le tournage d'un film, un tribunal; et les espaces s'interpénètrent, jusqu'à superposer deux scènes simultanément jouées. Lieux, dialogues, personnages, mais aussi temporalités se chevauchent. Après la Révolution française puis la Commune, c'est donc la guerre d'Algérie qui clôt cette ultime livraison qui pose la question du pardon. Ce qui se joue dans ce procédé (utilisé récemment par Sylvie Kandé ou Gauz) où l'actualité entre en résonance avec le passé, c'est l'opportunité d'arracher au bourbier de l'Histoire une autre histoire, un autre récit, comme le demandait déjà Alexis Jenni dans son magistral Art français de la guerre. Présent et passé sont mis en «résonance» (le mot est de Baptiste Amann). Il ne s'agit donc pas d'une reproduction fantasmé et mécanique. On n'enferme pas les mots des poètes (Baptiste Amman ou Magyd Cherfi) dans le coffre-fort des réductions et de l'entre-soi. "Je convoque l'Histoire dans une œuvre. J'extrais donc de l'Histoire ce dont l'œuvre a besoin et non l'inverse» explique sur scène le réalisateur à une journaliste-procureure, une «officiante du bavardage» (Sénac) qui ignore les changements à l'œuvre, le mouvement des appartenances/territoires, les recompositions épistémologiques, les mémoires à reconsidérer ou mieux, selon la dynamique proustienne, à laisser sourdre grâce aux circonstances et aux opportunités ("aux eaux troubles de la mémoire sont liées les intermittences du cœur»). Si, en France, le chemin est encore long, en Algérie, cette anamnèse sera moins du goût des officiels pickpockets d'une légitimité historique que des millions de manifestants qui défilent aussi pour se réapproprier leur Histoire. Avec à leur côté la toujours intègre et libre Djamila Bouhired. Un double symbole ici.

D'ailleurs, comment faire marcher, au pas des slogans, une créativité aussi ébouriffée, époilante? Sur cette scène multiforme et flexible, les thèmes se bousculent, sans confusion ni égarement: l'hôpital géré à la sauce libérale (d'où ce lucratif tournage), le don d'organes, les paroles survoltées d'une jeune actrice ou la sage considération d'un infirmier, le trouble des héritages, des filiations et des fidélités, jusqu'aux fécondes paraboles des éponges à crevettes ou du lierre et de l'arbre... Et bien sûr les émeutes; cette longue et douloureuse tirade où sont égrenés les noms et l'âge des jeunes 
français des cités morts depuis 40 ans. Dehors, les gamins cagoulés sont «les ombres de la République». Ils ont la «colère» pour territoire, «une tristesse qui s'ignore» et qui «nous éloigne chaque jour de nous-mêmes». Dans les couloirs de l'hôpital, les figurants d'une guerre lointaine croisent les acteurs d'une révolte bien réelle. Les images s'entrechoquent et la fiction devient enjeu politique: la violence verticale, sourde, aveugle, de l'autorité face au désespoir pour horizon: «lls tapent du poing sur la table. Nous fracassons le nôtre contre les murs.» Encore et toujours! Et la figure de Djamila Bouhired envahit l'espace de cet hôpital où la vie dépend des organes d'un mort. Du haut de sa trentaine, Baptiste Amann renouvelle tout simplement les genres et les approches. Il fallait sans doute être de cette génération. L'autre performance de cette pièce tient aux comédiens. Ils sont sept - Solal Bouloudnine, Alexandra Castellon, Naïlia Harzoune, Yohann Pisiou, Samuel Réhault, Lyn Thibault, Olivier Veillon - pour interpréter dix-sept personnages. Il faut de la souplesse, de la technique, des ressources, du fond et de l'étendue, du cœur et des couleurs à ces sept-là pour embarquer, deux heures durant, un public conquis; pour porter ce théâtre exigeant, dense, poétique, aux registres - des langues et des émotions - multiples.

Prochaines représentations:

Le 12 mars, L'Empreinte (Brive); du 18 au 20 mars, Théâtre Daniel Sorano (Toulouse); du 31 mars au 3 avril, Théâtre Dijon-Bourgogne.

M. H. 